\title{
Difficulties and Breakthroughs in Social Security of Lost Families
}

\author{
Zhou Yana \\ School of Finance, Yunnan University of Finance and Economics, Yunnan, China, 650221
}

Keywords: lost family; social security; predicament; breakthrough

Abstract: Because the psychological and social pressures of the family members of the families who have lost their independence are enormous, and the rights relief of the families who have lost their independence in China is still in the stage of continuous improvement, it is necessary to pay attention to this group. This paper studies the social dilemma of the special social group of the separated family from four aspects, and explores how to alleviate or solve the difficulties they face.

The main purpose of implementing family planning policy is to control population growth. However, the negative impact of the policy on society also needs to be paid attention to. The emergence of disability and death of one-child has led to the emergence of many groups of single-child families, resulting in a series of social problems that need to be solved urgently.

Table 1. China Health Statistics Yearbook 2013 issued by the State Health Planning Commission

\begin{tabular}{|c|c|c|}
\hline & Age group & mortality \\
\hline urbanite & 15-30 years old & 92.62 人/100000 \\
\hline Rural residents & $15-30$ years old & 228.26 人/100000 \\
\hline
\end{tabular}

As shown in table 1, it is estimated that the total number of separated families in China is more than one million. The communique of the Fifth Plenary Session of the Eighteenth Central Committee pointed out: "Promoting balanced population development, adhering to the basic national policy of family planning, improving population development strategy, implementing the policy of one couple having two children in an all-round way, and actively carrying out actions to deal with population ageing." This means that China's one-child policy, which has been implemented for more than 30 years, has come to an end. Through the analysis of the predicament faced by the group of lonely families, this paper explores the basic countermeasures for the relief of the rights of lonely families, with a view to providing theoretical reference for solving the social problems.

\section{The connotation of the lost family}

The so-called lone family, that is, the husband and wife of the family abide by the family planning policy and have only one child or adopt one child in their whole life. However, the child dies because of illness, accident and other reasons. The parents of the family are no longer able to 
bear, have children or adopt children. Most of the lonely people are beyond the age of 50 and have no ability to reproduce. After the death of the only child, they are under tremendous pressure in terms of pension and spiritual aspects. According to Mu Guantanamo, "The only-child family is essentially a high-risk family, and the risk lies in its uniqueness."

From the family level, on the one hand, the only child's risk of death, when the only child dies, their parents will be in the grief of losing their children because they have no other children; on the other hand, the risk of injury and illness, if the only child has the situation of injury and illness, then they can not support their parents, but also need the care of others, which will add enormous to the family. High pressure. In a high-risk one-child family, parents place their emotions almost exclusively on the only child. Once the above-mentioned risks arise, they will inevitably bring irreversible harm to the family. In the 1980s, when the family planning policy was implemented in China, most of the generation of people of childbearing age were entering the old age stage or have become the old people, among whom many have lost their independence. We must pay attention to these issues, the rights and interests of these families and their social plight.

\section{The Social Dilemma Facing the Lost Families}

When the only-child family becomes a lonely family, it will be inconceivable to bring economic, spiritual, social adaptation and the impact of life and old-age support to the lonely person, which can not be resolved by the individual family members.
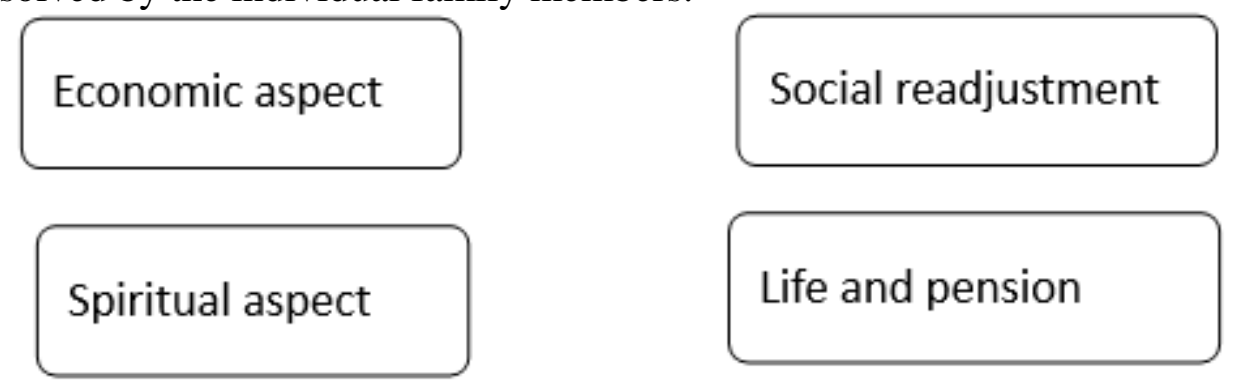

Figure 1. The Social Dilemma Facing the Lost Families

As shown in figure 1, the following will be a detailed analysis of the social plight faced by families who have lost their independence.

\subsection{Economic Aspects}

Every family needs funds to ensure its daily life. Because of the death of the only child in the family, the lonely people can not get their children back to their parents when they are adults. Li Shufti, director of the Institute of Population and Development of Xi'an Tongan University, said: "The level of economic support provided by children directly determines the life satisfaction and quality of life of rural elderly people." In China's rural areas, the social security system is not perfect enough, most of the elderly people do not leave the pension, their lives can not be separated from the support of their children. In cities and towns, the social security system is relatively perfect, and the elderly themselves have certain economic capacity. Even so, "many elderly people do not have pensions or retirement pensions, which exists in the situation of"one old man and two old men". Therefore, these elderly people still need the support of their children in order to enjoy their old age. However, the group who lost their independence can not enjoy the economic support provided by their children in their lives, which makes some groups who lost their independence face economic difficulties. Beginning in 2008, the policy of allowance for separated families began to be fully implemented in China: "After the wife reaches 49 years old, the couple will receive a special 
allowance of not less than 80 yuan (disability) or 100 yuan (death) per person per month." Over the next few years, the policy of allowance for lonely families divided different standards for rural and urban areas, while the standard of allowance has been improved. By 2016, the standard of allowance for the families who lost their independence in rural areas will be unified with that in urban areas, and it will be adjusted to 270 yuan per person per month (disability) and 340 yuan per person (death). Although the relevant policies issued by the state have paid attention to the economic aspects of the separated families, it is obvious that these subsidies are insufficient.

\subsection{Spiritual Aspects}

Children are the dependence and hope of parents, and the happiness they bring to the family is irreplaceable. The pain of losing their children is enormous for them, but because of the reasons of old age or ligation, the lonely can not have another child, so the psychological pain of the lonely group is irreversible. Most of the lonely people become silent after their children suffer accidents, their personality becomes inferior and isolated, and their communication with the outside world becomes less. All these are caused by the mental pain and trauma of the lonely group. Psychological studies have shown that older people actually need more colorful spiritual lives than young people struggling. The lonely need to be comforted by relatives and friends who support and help them, and pour out their heartache to them, because emotional communication and spiritual comfort are the most needed of the lonely group, and the spiritual needs of the lonely are the important issues that the society should pay attention to.

\subsection{Social readjustment}

After suffering family accidents, the spiritual pain of the lonely often makes them unable to face the real life. When they face the society again, the lonely will have psychological obstacles. After the change of family economic structure, some of the elderly who have already begun to provide for the aged have to find new jobs to support their livelihoods. However, age and physical conditions are a test for these lonely people. James Coleman, an American sociologist, believes that "different network relationships will provide different types of social support. Therefore, in order to ensure a large amount of social support for life, a person must maintain social relations with a variety of people." Therefore, facing and accepting the reality, going out of the family, going to the community and society, re-establishing confidence in life, conducting more social exchanges, re-proving self-worth, and pursuing the meaning of life are the starting points for the lonely to get out of the predicament and establish their self-identity.

\subsection{Life and pension}

Chinese people have a tradition of "raising children and preventing old age" since ancient times. As parents, their life can not be separated from their children's companionship and care. As part of the triangle of a well-structured one-child family, children play an important role in the family. Parents need their children to provide for the aged. Especially for the elderly, their self-care ability is gradually declining. The difficulties in clothing, food, housing and transportation are also increasing. In many aspects of life, they need the help and care of their children. There are also some elderly people, because of senility, sickness, and even need the constant care and companionship of their children. Losing children, their impact and life pressure are social problems that can not be ignored. 


\section{Multi-Purpose: Improving Social Security Measures for Lost Families}

\subsection{There are Rules to Follow: Refine and Improve Relevant Laws and Regulations}

We should improve the legal provisions on the pension of lonely families, clarify the rights and interests of lonely groups, and divide the responsibilities of relevant functional departments. In the process of implementation, local governments should formulate detailed implementation rules and implementation plans, make full use of the development results of the Internet, build a platform for sharing relief information, smooth the channels of relief for single families, and gradually form a long-term support mechanism for single families. For those who have lost their independence, the restrictions on receiving compensation should be relaxed appropriately, and more people who need it but cannot receive it will be helped. Local governments should set up special inspection teams in discipline inspection departments to inspect and supervise the implementation of the policy of helping families who have lost their independence and the distribution of funds.

\subsection{Economic Support: Establishing Diversified Assistance Mechanism}

The state should establish a diversified financing mechanism for the assistance of families who have lost their independence, not rely solely on state subsidies. It should make use of the network and the media to publicize and report, so that more loving people and enterprises can participate in the assistance action. We should establish a strict supervision and distribution mechanism for social donation of relief funds, and timely announce the flow of funds so that the funds can be properly used. On the other hand, when granting one-time pension, the government should consider the local economic development and the level of objects as appropriate, raise the standard of payment to the greatest extent possible, and grant a certain amount of nursing subsidy to the elderly who need to provide old-age support, poor self-care ability and financial difficulties.

\subsection{Social Support: Establishment and Expansion of Social Support Service Team}

Make full use of social forces to achieve twice the result with half the effort. For example, while providing material help to families, the community should also provide normal spiritual comfort. The community should be equipped with specific staff to supervise and evaluate the services provided by social organizations. The District (county) government should establish Hatcheck Groups and Activity Centers to facilitate communication and communication, and guide the lost parents to rebuild confidence and hope in mutual assistance. Hope: For the elderly parents who need daily care, they can carry out propaganda among other social organizations, such as housekeeping centers, community organizations and volunteer organizations, select some people who are willing to help the parents to take care of them, and pay a certain amount of subsidies. On the other hand, people from all walks of life actively participated in this activity, which made the lost parents feel the warmth of society, and also provided great spiritual comfort to this special group.

\section{Conclusion}

Compared with the normal family, the elderly who are alone need to endure more mental suffering. Therefore, the government should increase the proportion of medical subsidies to them and set up necessary medical insurance subsidies. In addition, exercise equipment should be installed in the community and emergency call devices should be installed in the homes of the elderly who have lost their independence so that they can get timely help in case of sudden illness. All walks of life, especially the medical and health departments, should spontaneously organize 
medical and nursing teams, go into the families of lonely people, do regular free health checkups for them, and answer health problems.

\section{Acknowledgement}

Research on the impact of Longevity risk on the Sustainable Development of Endowment Insurance: a case study of Yunnan Province, No.: 2018JS319)

\section{References}

[1]Bhang Taichung, Chen Weeing. Change and Adjustment: Maintenance Logic of Family Stability of Lost Only Parents --- Consideration from the Perspective of Family Dynamics [J]. Journal of Central China Normal University (Humanities and Social Sciences Edition), 2013 (3).

[2]Mu Guantanamo. Self-salvation and social salvation of the lost parents [J]. Journal of China Agricultural University (Social Science Edition), 2015 (3).

[3]Ran Weenie, Chen Quango. The plight of the elderly and the construction of social support system for the lost parents [J]. New horizon, 2015 (3).

[4]Chi Shush. Research on Social Assistance for the Elderly in "Lost Families" in China [J]. Dong Yue Len Cong, 2017 (8).

[5]Ding Hongi, Bi Ding. Reflections on How to Pay Attention to the Old-age Problem of "Lost Family"[J]. Lanzhou Academic Journal, 2013 (4). 